\title{
Complications and Survival Rate of Patients Over 80 Years Old Who Underwent Laparoscopic Gastrectomy for Gastric Cancer
}

\author{
Ki Hyun Kim, M.D. ${ }^{1}$, Si Hak Lee, M.D., Ph.D. ${ }^{1}$, Cheol Woong Choi, M.D., Ph.D. ${ }^{2}$, Su Jin Kim, M.D. ${ }^{2}$, Dae Gon Ryu, M.D. ${ }^{2}$, \\ Chang In Choi, M.D., Ph.D. ${ }^{3}$, Dae Hwan Kim, M.D., Ph.D. ${ }^{3}$, Tae Yong Jeon, M.D., Ph.D. ${ }^{3}$, Dong Heon Kim, M.D., Ph.D. ${ }^{3}$, \\ Sun Hwi Hwang, M.D., Ph.D. ${ }^{1}$ \\ Departments of ' Surgery, ${ }^{2}$ Internal Medicine, Pusan National University Yangsan Hospital, Yangsan, ${ }^{3}$ Department of Surgery, Pusan National University, \\ Busan, Korea
}

Purpose: As the life expectancy increases, the population of elderly patients increases. We evaluated the complications and survival rate of patients over 80 years old, who underwent laparoscopic gastrectomy.

Methods: A retrospective analysis was conducted for a total of 1,912 patients, who underwent surgery with stomach cancer from 2008 to 2016. We analyzed postoperative complications and the survival rate between the middle old (70 79, $\mathrm{n}=255$ ) group and the very old ( $\geq 80, \mathrm{n}=37$ ) group.

Results: Among 1,912 patients, 255 people in the middle old group and 37 people within the very old group underwent laparoscopic gastrectomy. We confirmed that there was no significant difference except for the age $(p<0.001)$ between the two groups. Overall complications were not statistically significantly different between the Middle old (70 79) group and the very old ( $\geq 80$ ) group, $11.8 \%$ and $16.2 \%$, respectively. There were also no statistically significant differences in severe complications beyond Clavien-Dindo classification Grade III. Risk factors for overall complications were higher in males than in females $(p=0.002)$. Overall survival was statistically significantly lower with very old group $(p<0.001)$.

Conclusion: Laparoscopic gastrectomy in gastric cancer patients over 80 years of age is feasible and safe in terms of complications. However, considering the life expectancy, it seems necessary to pay attention to the patients who apply surgery.

Keywords: Elderly, Stomach cancer, Complications, Gastrectomy

This is an Open Access article distributed under the terms of the Creative Commons Attribution Non-Commercial License (http:// creativecommons.org/licenses/by-nc/4.0/) which permits unrestricted non-commercial use, distribution, and reproduction in any medium, provided the original work is properly cited.
Received September 11, 2017

Revised October 16, 2017

Accepted November 7, 2017

Corresponding author

Sun Hwi Hwang

Department of Surgery, Pusan

National University Yangsan

Hospital, 20 Geumo-ro, Moolgeum-

eup, Yangsan 50612, Korea

Tel: +82-55-360-2124

Fax: +82-55-360-2154

E-mail: hwangsh@pusan.ac.kr

\section{INTRODUCTION}

The number of elderly population is increasing worldwide, and the number of elderly patients with gastric cancer also increases. ${ }^{1}$ Similarly, in South Korea, in the statistics of patients who underwent gastrectomy, the percentage of patients aged 71 or over increased to $9.1 \%$ in 2009 and $25.3 \%$ in 2014. ${ }^{2}$
In a study of patients over 80 years of age, surgical treatment has shown a better prognosis over supportive care. ${ }^{3}$ However, due to the concerns of postoperative complications and mortality, there are many difficulties in decision of surgical treatment. ${ }^{4.5}$

In this study, we divided the middle old (70 79) group and the very old $(\geq 80)$ group to compare postoperative complica- 
tions and the survival rate between the two groups.

\section{MATERIALS AND METHODS}

\section{Patients}

In this retrospective study, from September 2008 to December 2016, 1,912 patients who underwent gastrectomy with gastric cancer at 00000 University, 0000 hospital were included. Patients were divided into middle old (70 79, n=255) group and the very old $(\geq 80, n=37)$ group. ${ }^{6}$ Patients were included, who only underwent laparoscopic gastrectomy.

All patients underwent D1+or D2 lymph node dissection, according to the guidelines of the Japanese Society of Gastric Cancer. The surgical method was selected by the surgeon, according to the location of cancer lesion and the condition of the patient. The resection method and anastomosis method(Biloth I, Billoth II, Roux-en Y) were determined by the surgeon according to the situation of the operation filed. Proximal gastrectomy used double tract reconstruction. Most patients were treated according to a standardized clinical pathway. On the second POD, patients were allowed to start drinking clear fluid. On the third POD, a soft diet was started to patients. Drainage tubes were removed after soft diet if the drainage fluid was clear.

Postoperative complications were classified to ClavienDindo classification. ${ }^{8}$ Severe complications defined as higher than grade III. The average follow-up period was $28.3 \pm 20.8$ months (range 0 97 months).

\section{Statistical analysis}

Statistical analysis was performed using IBM SPSS Statistics ver. 21.0 (IBM Co., Armonk, NY, USA).

Patient age, gender, American Society of Anesthesiologist (ASA), tumor size, Operative time, body mass index (BMI), No. of resected lymph nodes, Comorbidity, TNM stage according to the 7th TNM classification, ${ }^{9}$ Extent of Operation, overall survival was included in the analysis. Differences between the two groups were analyzed using the Student's t test for continuous variables and the Chi square or Fisher's exact tests for proportions. Patient survival was evaluated using the Kaplan-Meier method and analyzed using the log-rank tests. A $p$ value $<0.05$ from the two-tailed test was defined significant.
Table 1. Clinicopathologic characteristics of two groups

\begin{tabular}{|c|c|c|c|}
\hline Variables & $\begin{array}{c}\text { Age }(70 \sim 79) \\
\quad(n=255)\end{array}$ & $\begin{array}{c}\text { Age }(\geq 80) \\
(n=37)\end{array}$ & $p$ value \\
\hline Age, year & $73.8 \pm 2.7$ & $81.3 \pm 1.5$ & $<0.001$ \\
\hline Sex & & & 0.329 \\
\hline Male & $139(54.5)$ & $17(45.9)$ & \\
\hline Female & $116(45.5)$ & $20(54.1)$ & \\
\hline ASA SCORE & & & 0.559 \\
\hline 1 & $39(15.4)$ & $8(21.6)$ & \\
\hline 2 & $198(78.0)$ & $26(77.0)$ & \\
\hline 3 & $17(6.7)$ & $3(8.1)$ & \\
\hline Tumor size, cm & $3.4 \pm 2.3$ & $3.5 \pm 2.3$ & 0.791 \\
\hline Operative time, min & $191.5 \pm 43.6$ & $183.8 \pm 33.3$ & 0.210 \\
\hline Body mass index, $\mathrm{kg} / \mathrm{m}^{2}$ & $23.9 \pm 3.5$ & $22.8 \pm 2.4$ & 0.720 \\
\hline No. of resected lymph nodes & $30.4 \pm 11.8$ & $29.8 \pm 11.3$ & 0.769 \\
\hline Estimated blood loss, ml & $90.8 \pm 64.0$ & $102.7 \pm 96.3$ & 0.142 \\
\hline Comorbidity & & & 0.858 \\
\hline Yes & $156(61.2)$ & $22(59.5)$ & \\
\hline No & $99(38.8)$ & $15(40.5)$ & \\
\hline T stage & & & 0.576 \\
\hline $\mathrm{T} 1$ & $194(76.1)$ & $25(67.6)$ & \\
\hline Т2 & $27(10.6)$ & $4(10.8)$ & \\
\hline Т3 & $19(7.5)$ & $4(10.8)$ & \\
\hline T4 & $15(5.9)$ & $4(10.8)$ & \\
\hline $\mathrm{N}$ stage & & & 0.480 \\
\hline NO & $195(76.5)$ & $27(73.0)$ & \\
\hline N1 & $35(13.7)$ & $4(10.8)$ & \\
\hline N2 & $17(6.7)$ & $3(8.1)$ & \\
\hline N3 & $8(3.1)$ & $3(8.1)$ & \\
\hline Stage, $n$ & & & 0.196 \\
\hline I & $200(78.4)$ & $27(73.0)$ & \\
\hline$\|$ & $37(14.5)$ & $4(10.8)$ & \\
\hline III & $18(7.1)$ & $6(16.2)$ & \\
\hline Extent of operation & & & 0.481 \\
\hline Distal gastrectomy & $225(88.2)$ & $35(13.5)$ & \\
\hline Total gastrectoym & $17(6.7)$ & $0(0)$ & \\
\hline Proximal gastrectomy & $13(5.1)$ & $2(5.4)$ & \\
\hline
\end{tabular}




\section{RESULTS}

\section{Clinicopathologic characteristics}

Clinicopathologic findings of the 292 patients are summarized in Table 1. The average age in the middle old group was $73.8 \pm 2.7$ years, while the average age in very old group was $81.3 \pm 1.5$ years (range, 80 84 years; $p<0.001$ ). There was no statistical difference between the two groups for gender, American Society of Anesthesiologist (ASA), tumor size, Operative time, body mass index (BMI), No. of resected lymph nodes, Comorbidity, TNM stage according to the 7th TNM classification (9), Extent of Operation.

\section{Postoperative outcomes}

Postoperative outcomes are shown in Table 2. Overall complications (grade II or higher) occurred with similar frequency in the middle old group and very old groups (11.8 vs. $16.20 \%$; $p=0.426$ ). Severe complications (grade III or higher) were also similar between the 2 groups (6.7 vs. $5.4 \% ; p=1.000$ ). The 2 groups were similar in terms of operation time. The 2 groups were similar in terms of hospital stay, time to first flatus, mortality. The cause of death of the mortality case of very old group is pneumonia.

\section{Risk factors for complication in elderly patients}

Risk factors for complication in elderly patients in Table 3. Risk factors for overall complications (grade I or higher) in the elderly patients ( $\geq 70$ years) were only gender, in the uni-

Table 2. Postoperative outcomes with morbidity and mortality according to group

\begin{tabular}{|c|c|c|c|}
\hline & $\begin{array}{c}\text { Age }(70 \sim 79) \\
(\mathrm{n}=255)\end{array}$ & $\begin{array}{c}\text { Age }(\geq 80) \\
(n=37)\end{array}$ & $p$ value \\
\hline \multicolumn{3}{|c|}{ Overall complication (grade I or higher ${ }^{a}$ ) } & 0.426 \\
\hline No & $225(88.2)$ & $31(83.8)$ & \\
\hline Yes & $30(11.8)$ & $6(16.2)$ & \\
\hline \multicolumn{4}{|c|}{ Severe complication (grade III or higher") } \\
\hline No & 238 (93.3) & $35(94.6)$ & 1.000 \\
\hline Yes & $17(6.7)$ & $2(5.4)$ & \\
\hline Hospital stay, days & $11.4 \pm 8.4$ & $11.9 \pm 5.8$ & 0.937 \\
\hline Time to first flatus & $3.3 \pm 1.6$ & $3.8 \pm 2.1$ & 0.098 \\
\hline Mortality & 0 & $1(2.7)^{\mathrm{b}}$ & 0.127 \\
\hline
\end{tabular}

${ }^{a}$ Clavien-Dindo classification; ${ }^{\mathrm{b}}$ Peumonia. variable analysis [Odds ratio 1.4, $95 \%$ confidence interval (CI) $0.7 \sim 2.8 ; p=0.002$ ]. There are no risk factors for severe complications (grade III or higher) in elderly patients ( $\geq 70$ years).

\section{Survival of middle old (70 79) and very old ( $\geq 80)$ patients}

Fig. 1 shows the overall survival of middle old (70 79) and very old $(\geq 80)$ patients. The mean follow-up period was $86.3 \pm 2.7$ months (95\% confidence interval [CI], 83.8 93.9

Table 3. Risk factors for complication in elderly patients

\begin{tabular}{|c|c|c|c|c|}
\hline & Overall & complicati & on (grade I or hig & her ${ }^{\mathrm{a}}$ ) \\
\hline & $\begin{array}{c}\text { No } \\
(n=256)\end{array}$ & $\begin{array}{c}\text { Yes } \\
(n=36)\end{array}$ & $\begin{array}{l}\text { Odds ratio } \\
\text { (95\% Cl) }\end{array}$ & $p$ value \\
\hline Age, years & & & & 0.426 \\
\hline $70 \sim 79$ & $225(87.9)$ & $30(83.3)$ & & \\
\hline$\geq 80$ & $31(12.1)$ & $6(16.7)$ & & \\
\hline Sex & & & $1.4(0.7 \sim 2.8)$ & 0.002 \\
\hline Male & $128(50.0)$ & $28(77.8)$ & & \\
\hline Female & 128 (50.0) & $8(22.2)$ & & \\
\hline Estimated blood loss & ml & & & 0.098 \\
\hline$<100$ & 198 (77.3) & $27(75.0)$ & & \\
\hline$\geq 100$ & 58 (22.7) & $9(25.0)$ & & \\
\hline Body mass index, $\mathrm{kg}$ & $/ \mathrm{m}^{2}$ & & & 0.459 \\
\hline$<25$ & $167(65.2)$ & $21(58.3)$ & & \\
\hline$\geq 25$ & 89 (34.8) & $15(41.7)$ & & \\
\hline ASA score & & & & 0.732 \\
\hline 1,2 & 238 (93.0) & $33(91.7)$ & & \\
\hline 3 & $18(7.0)$ & $3(8.3)$ & & \\
\hline Comorbidities & & & & 0.855 \\
\hline No & 99 (38.7) & $15(41.7)$ & & \\
\hline Yes & 157 (61.3) & 21 (58.3) & & \\
\hline Extent of resection & & & & 0.704 \\
\hline$D G, P G$ & 240 (93.8) & $35(97.2)$ & & \\
\hline TG & $16(6.3)$ & $1(2.8)$ & & \\
\hline pN stage & & & & 1.000 \\
\hline NO & $192(75.0)$ & 30 (83.3) & & \\
\hline $\mathrm{N} 1 \sim \mathrm{N} 3$ & $64(25.0)$ & $6(16.7)$ & & \\
\hline TNM stage & & & & 1.000 \\
\hline I, II & 235 (91.8) & $33(91.7)$ & & \\
\hline III & $21(8.2)$ & $3(8.3)$ & & \\
\hline
\end{tabular}


Table 3. Continued

\begin{tabular}{|c|c|c|c|c|}
\hline & Severe cor & mplication ( & grade III or $\mathrm{h}$ & higher ${ }^{a}$ ) \\
\hline & $\begin{array}{c}\text { No } \\
(\mathrm{n}=273)\end{array}$ & $\begin{array}{c}\text { Yes } \\
(n=19)\end{array}$ & $\begin{array}{l}\text { Odds ratio } \\
\text { (95\% CI) }\end{array}$ & $p$ value \\
\hline Age, years & & & & 1.000 \\
\hline $70 \sim 79$ & $238(87.2)$ & $17(89.5)$ & & \\
\hline$\geq 80$ & $35(12.1)$ & $2(10.5)$ & & \\
\hline Sex & & & & 0.095 \\
\hline Male & 142 (52.0) & $14(73.7)$ & & \\
\hline Female & $131(48.0)$ & $5(26.3)$ & & \\
\hline Estimated blood loss, ml & & & & 0.131 \\
\hline$<100$ & $211(77.3)$ & $14(73.7)$ & & \\
\hline$\geq 100$ & $62(22.7)$ & $5(26.3)$ & & \\
\hline Body mass index, $\mathrm{kg} / \mathrm{m}^{2}$ & & & & 0.704 \\
\hline$<25$ & $175(64.1)$ & $13(68.4)$ & & \\
\hline$\geq 25$ & $98(35.9)$ & $6(31.6)$ & & \\
\hline ASA score & & & & 1.000 \\
\hline 1,2 & 253 (92.7) & $18(94.7)$ & & \\
\hline 3 & $20(7.3)$ & $1(5.3)$ & & \\
\hline Comorbidities & & & & 0.472 \\
\hline No & $105(38.5)$ & $9(47.4)$ & & \\
\hline Yes & $168(61.5)$ & $10(52.6)$ & & \\
\hline Extent of resection & & & & 1.000 \\
\hline $\mathrm{DG}, \mathrm{PG}$ & $257(94.1)$ & $18(94.7)$ & & \\
\hline TG & $16(6.3)$ & $1(2.8)$ & & \\
\hline pN stage & & & & 1.000 \\
\hline NO & $207(75.8)$ & $15(78.9)$ & & \\
\hline $\mathrm{N} 1 \sim \mathrm{N} 3$ & $66(24.2)$ & $4(21.1)$ & & \\
\hline TNM stage & & & & 1.000 \\
\hline I, II & $250(91.6)$ & $18(94.7)$ & & \\
\hline III & $23(8.4)$ & $1(5.3)$ & & \\
\hline
\end{tabular}

${ }^{a}$ Clavien-Dindo classification; $\mathrm{Cl}=$ confidence interval; $\mathrm{ASA}=$ American Society of Anesthesiologist; $D G=$ distal gastrectomy; $P G=$ proximal gastrectomy; $\mathrm{TG}=$ total gastrectomy.

months); patients in the middle old group had a mean overall survival of $88.8 \pm 2.6$ months (95\% CI, 83.8 93.9 months); while patients in the very old group had a mean overall survival of $37.0 \pm 2.8$ months (95\% CI, 31.5 42.4 months). Overall survival of the very old group was worse than the middle old group $(p<0.001)$.

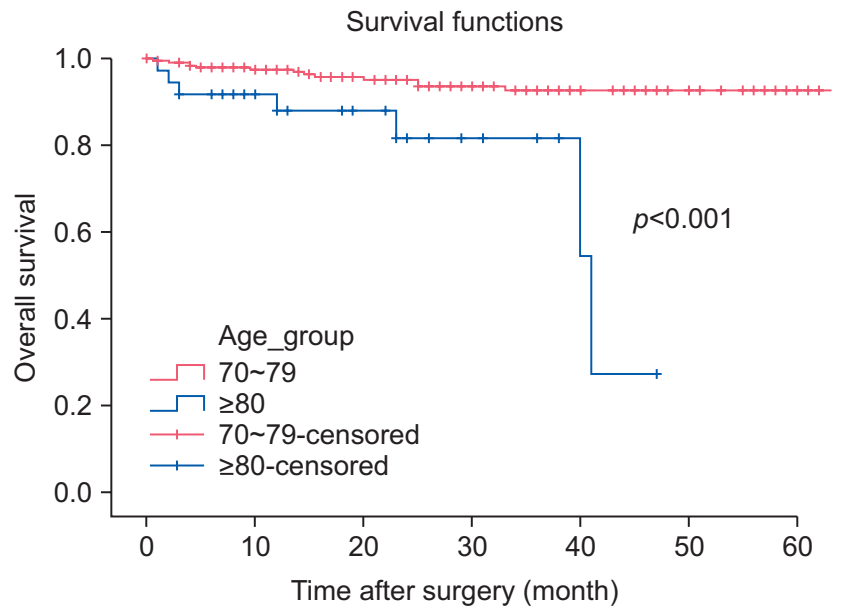

Fig. 1. Overall survival of middle old $(70 \sim 79)$ and very old $(\geq 80)$ Patients.

\section{DISCUSSION}

The definition of the elderly has not been established yet. It is also the definition of elderly patients. It is classified as being over 70 years old, ${ }^{10,11}$ over 75 years old, ${ }^{4,12}$ over 80 years old ${ }^{13,14}$ by each research. As the life expectancy increases, patients who underwent surgery with stomach cancer tend to be increasing. ${ }^{2}$ The expected life expectancy of the population over 80 years old is 9.5 years: 8.0 years and 10.3 years in men and women, respectively. ${ }^{15}$ In this study, we followed the classification of research defined by middle old and very old in the definition of elderly people. ${ }^{6}$

Gastric cancer occurs more frequently in men. In our study, the middle old group reflects these tendencies well (male:female $=54.5 \%: 46.5 \%$ ). However, these male-female ratios are the opposite in the very old group (male:female $=$ 45.9\%:54.1\%). It seems that women's average life expectancy is higher than men's life expectancy. For each group, there are no other statistical differences. The number of resected lymph nodes in the middle old group was like very old group $(p=0.769)$. These results reflect that both groups lymph node dissection was properly implemented.

Overall, complication had no statistical significance, but very old group showed high frequency (11.8\% vs $16.2 \%)$. On the other hand, severe complication showed low frequency of very old group (6.7\% vs 5.4\%). This seems to be the result of selection bias of the very old group. Patients with relatively good performance tend to undergo surgery. There is no difference between the ASA scores of both groups, which evidence supports this.

There are reports of an advanced stage of tumor growth, ${ }^{16}$ prolonged operation times and excessive blood loss,17 gender (male), ${ }^{13}$ ASA score ${ }^{14}$ as independent prognostic factors affect- 
ing complications in elderly patients. In this study, only Gender (male) was risk factor in complications with univariable analysis. A man is higher in visceral obesity than women ${ }^{18}$ and is exposed to many risk factors such as smoking and drinking, from a cultural environment. ${ }^{19}$ There was one mortality in this study. An 83-year-old male patient without comorbidities, it was death from pneumonia. The postoperative care of elderly patients should carefully manage even unpredictable problems.

The mean overall survival of very old group in this study was 37.0 \pm 2.8 months (95\% CI, 31.5 42.4 months). Overall, survival of the very old group was worse than the middle old group $(p<0.001)$. Most of the deaths of the very old group were caused by natural cause, or other diseases, and not due to gastric cancer. The reason why the treatment plan cannot be easily applied to elderly patients is that there are many unpredictable variables. From the results of this study, laparoscopic gastrectomy is a safe and useful surgical procedure for gastric cancer patients over 80 years of age However, from the standpoint of survival, it seems to be necessary to use a customized treatment strategy for each patient. Elderly patients, who are judged to be able to undergo surgical treatment, are thought to be useful for aggressive treatment.

This study has several limitations. Firstly, relatively well function patients who performed surgery. Secondly, the number of patients over 80 years old is small. Therefore, prospective studies on treatment strategies for elderly patients are needed.

Laparoscopic gastrectomy in gastric cancer patients over 80 years of age is feasible and safe in terms of complications. However, patients with the elderly have many unpredictable variables and it is difficult to predict life expectancy, so survival benefit must be considered carefully. Also, since there are possibilities that various problems may arise after surgery, it seems that more detailed post-operative care will be necessary.

\section{ACKNOWLEDGMENTS}

This study was supported by Research institute for Convergence of biomedical science and technology (30-2014-014), Pusan University Yangsan Hospital.

\section{REFERENCES}

1) Takeshita H, Ichikawa D, Komatsu S, et al. Surgical outcomes of gastrectomy for elderly patients with gastric cancer. World J Surg 2013;37:2891-2898.

2) Information Committee of Korean Gastric Cancer Association. Korean Gastric Cancer Association Nationwide Survey on Gastric Cancer in 2014. J Gastric Cancer 2016;16:131-140.
3) Matsushita I, Hanai H, Kajimura M, et al. Should gastric cancer patients more than 80 years of age undergo surgery? Comparison with patients not treated surgically concerning prognosis and quality of life. J Clin Gastroenterol 2002;35:29-34.

4) Eguchi T, Takahashi Y, Ikarashi M, Kasahara M, Fujii M. Is extended lymph node dissection necessary for gastric cancer in elderly patients? Eur J Surg 2000;166:949-953.

5) Hamel MB, Henderson WG, Khuri SF, Daley J. Surgical outcomes for patients aged 80 and older: morbidity and mortality from major noncardiac surgery. J Am Geriatr Soc 2005;53:424-429.

6) Forman DE, Berman AD, McCabe CH, Baim DS, Wei JY. PTCA in the elderly: the "young-old" versus the "old-old". J Am Geriatr Soc 1992;40:19-22.

7) Japanese Gastric Cancer Association. Japanese classification of gastric carcinoma: 3rd English edition. Gastric Cancer 2011;14:101-112.

8) Clavien PA, Camargo CA, Jr., Croxford R, Langer B, Levy GA, Greig PD. Definition and classification of negative outcomes in solid organ transplantation. Application in liver transplantation. Ann Surg 1994;220:109-120.

9) Edge SB, Compton CC. The American Joint Committee on Cancer: the 7th edition of the AJCC cancer staging manual and the future of TNM. Ann Surg Oncol 2010;17:1471-1474.

10) Cho GS, Kim W, Kim HH, Ryu SW, Kim MC, Ryu SY. Multicentre study of the safety of laparoscopic subtotal gastrectomy for gastric cancer in the elderly. Br J Surg 2009;96:1437-1442.

11) Hwang SH, Park DJ, Jee YS, et al. Risk factors for operative complications in elderly patients during laparoscopy-assisted gastrectomy. J Am Coll Surg 2009;208:186-192.

12) Orsenigo E, Tomajer V, Palo SD, et al. Impact of age on postoperative outcomes in 1118 gastric cancer patients undergoing surgical treatment. Gastric Cancer 2007;10:39-44.

13) Kim MS, Kim S. Outcome of Gastric Cancer Surgery in Elderly Patients. J Gastric Cancer 2016;16:254-259.

14) Yang JY, Lee HJ, Kim TH, et al. Short- and Long-Term Outcomes After Gastrectomy in Elderly Gastric Cancer Patients. Ann Surg Oncol 2017;24:469-477.

15) Statistics Korea. Life tables [Internet]. Daejeon: Statistics Korea; 2016 [cited on Aug 1, 2017]. Available from: http://kosis.kr/ statHtml/statHtml.do?orgId=101\&tblId=DT_1B42\&conn_path=I2.

16) Bittner R, Butters M, Ulrich M, Uppenbrink S, Beger HG. Total gastrectomy. Updated operative mortality and long-term survival with particular reference to patients older than 70 years of age. Ann Surg 1996:224:37-42.

17) Habu H, Endo M. Gastric cancer in elderly patients--results of surgical treatment. Hepatogastroenterology 1989;36:71-74.

18) Kim JA, Choi CJ, Yum KS. Cut-off values of visceral fat area and waist circumference: diagnostic criteria for abdominal obesity in a Korean population. J Korean Med Sci 2006;21:1048-1053.

19) Sung NY, Choi KS, Park EC, et al. Smoking, alcohol and gastric cancer risk in Korean men: the National Health Insurance Corporation Study. Br J Cancer 2007;97:700-704. 